\title{
Sticky Bacteria: The Mini-Factories of Gums
}

\author{
Girish B Mahajan ${ }^{1 *}$ and Dipali Rahul Phatak ${ }^{2}$ \\ ${ }^{1}$ HiMedia Laboratories Pvt. Ltd., Mumbai, India \\ ${ }^{2} J o g e s h w a r i$ Education Society, Mumbai, India \\ *Corresponding Author: Girish B Mahajan, HiMedia Laboratories Pvt. Ltd., Mumbai, \\ India.
}

Received: May 15, 2021

Published: June 04, 2021

(C) All rights are reserved by Girish B

Mahajan and Dipali Rahul Phatak.

\begin{abstract}
Microbial polysaccharides or gums are classified as, exocellular, cell wall, and intercellular. Within the cell, they play a unique role in controlling energy resources, overcoming water stress, protective function, etc. However, due to their unique gelling and viscosity properties and neutral activities, they find wide applications in our day-to-day life. Several of today's foods and pharmaceuticals require unique texturization, viscosity, flavor releaser, appearance, and water-control properties. These polysaccharides are incorporated into foods and pharma products as thickeners, gelling agents, and agents to control ice crystal formation in frozen foods. Despite the great diversity of molecular structures, only a few microbial gums have been commercially developed. In the quest for new polysaccharides with better qualities for the above applications, the present research is bent towards exploiting new sources of polysaccharides especially from marine extremophilic and xerophytic microorganisms.
\end{abstract}

Keywords: Bacteria; Gums; Polymers

\section{Introduction to Sticky Bacteria}

We often encounter sticky barks of some trees, stickiness appearing in rice, curry, or cooked vegetables after long storage, especially during summer. Sometimes we see curd become too gluey and long strings stretch out when we take out the spoon from the curd. Well, all these examples are related to gums produced by certain bacteria. Often, we hear about plant gums such as: gum arabic, gum karaya, gum ghatti, and gum tragacanth, guar gum, locust bean gum, tara gum, and tamarind gum, etc. and synthetic gums. However, it is interesting to note that 1 - 5 micrometer long bacteria, the tiny life on the planet earth also produce a variety of gums, i.e. biopolymers, technically known as polysaccharides.

Polysaccharides are high molecular weight polymers of sugars. A majority of these are water-soluble having unique physical properties. Microbial polysaccharides are classified as, exocellular, cell wall, and intercellular. The exocellular polysaccharides are those that diffuse out from the bacterial cell into the culture medium. The cell wall i.e., structural and intercellular polysaccharides are integral parts of the cell envelope or capsular products. Within the cell, they play a unique role in controlling energy resources, overcoming water stress, protective function, etc. However, due to their unique gelling and viscosity properties and neutral activities, they find wide applications in our day-to-day life. Exopolysaccharides (EPS) such as xanthan gum, scleroglucan, gellan gum, curdlan, bacterial alginate, dextran, pullulan, bacterial cellulose, etc. are already successfully used in the food industry, medicines, pharmacy, cosmetics, and the oil exploration industry.

\section{History of bacterial polysaccharides/gums}

During the mid-19 $9^{\text {th }}$ century bacterial gum was discovered in the form of an exopolysaccharide in wine produced by Leuconostoc 
mesenteroides, which is now known as dextran. Over the course of time other exopolysaccharides such as cellulose, alginate, and xanthan were discovered. Production of these gums through massive capacity fermentors has been challenged due to several reasons. Advancement in bioreactors with impellers and sparging designs to modulate online rheological properties (example, viscocity) enhanced the ease of the scale-up of any bacterial polysaccharides.

What is the chemistry of microbial gums?

Most microbial gums are straight and continuous chain heteropolysaccharides consisting of three to seven different monosaccharides (sugar units) arranged in groups of 10 or less to form repeating units. Monosaccharides may be pentoses ( 5 carbon containing sugars), hexoses (6 carbon containing sugars), amino sugars, or uronic acids, etc. The molecular structure below demonstrates the arrangements of sugar units. Alginate, a polysaccharide is made of repeating units of Guluronic acid and mannuronic acid, Dextran is made up of glucose units with unique linkages and levan is made up of fructose units.

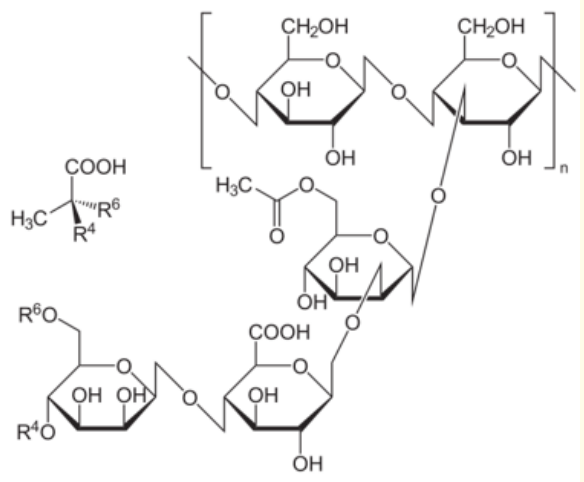

Figure 1: Xanthan gum: The primary structure is composed of a backbone of 1,4-linked $\beta$-D-glucose with side chains containing two mannose and one glucuronic acid.

The following table displays microbial source and respective gums along with their unique properties.

\begin{tabular}{|c|c|c|c|}
\hline Microbial Gum & Producer bacteria & Name of sugar units & $\begin{array}{l}\text { Molecular weight (Dal- } \\
\text { tons) }\end{array}$ \\
\hline Alginate & $\begin{array}{c}\text { Pseudomonas aeruginosa, Azotobacter } \\
\text { vinelandii }\end{array}$ & Guluronic acid, Mannuronic acid & $1000-1400 \mathrm{~K}$ \\
\hline Curdlan & $\begin{array}{l}\text { Alcaligenes faecali, Cellulomonas flaui- } \\
\text { gena }\end{array}$ & Glucose & $5 \times 10^{4}-2 \times 10^{6}$ \\
\hline Dextran & Leuconostoc mesenteroides & Glucose & $10^{6}-10^{8}$ \\
\hline Gellan & Sphingomonas paucimobilis & Glucose, Rhamnose, Glucuronic acid & $5 \times 10^{6}$ \\
\hline Hyaluronan & $\begin{array}{c}\text { Pseudomonas aeruginosa, Pasteurella } \\
\text { multocida }\end{array}$ & Glucuronic acid, Acetylglucosmine & $>5000$ \\
\hline Levan & Bacillus subtilis, Zymomonas mobili & Fructose & $<10^{8}$ \\
\hline Xanthan & Xanthomonas campestris & $\begin{array}{l}\text { Glucose, Mannose Glucuronic, Acid, } \\
\text { Acetate, Pyruvate }\end{array}$ & $2.0-50 \times 10^{6}$ \\
\hline
\end{tabular}

Table 1

Why do some bacteria produce gums/polysaccharides?

The primary reasons why bacteria produce gums is for prevention of the cell from desiccation and enhancing their survival in low water stress. These secreted gums help bacteria in adherence to surfaces and enhance better interactions with substrate. The heavy and smooth gum layer provides resistance to host immunity. In general, it permits the bacterium to survive harsh conditions be it in the external environment or inside a host. The polysaccharide facilitates biofilm formation and helps in the spread of the bacteria.
Where are these gums used?

Several of today's foods and pharmaceuticals require unique texturization, viscosity, flavour releaser, appearance, and watercontrol properties. These polysaccharides are incorporated into foods and pharma products as thickeners, gelling agents, and agents to control ice crystal formation in frozen foods. The following figure will demonstrate the diverse and unique applications of some bacterial polysaccharides. 


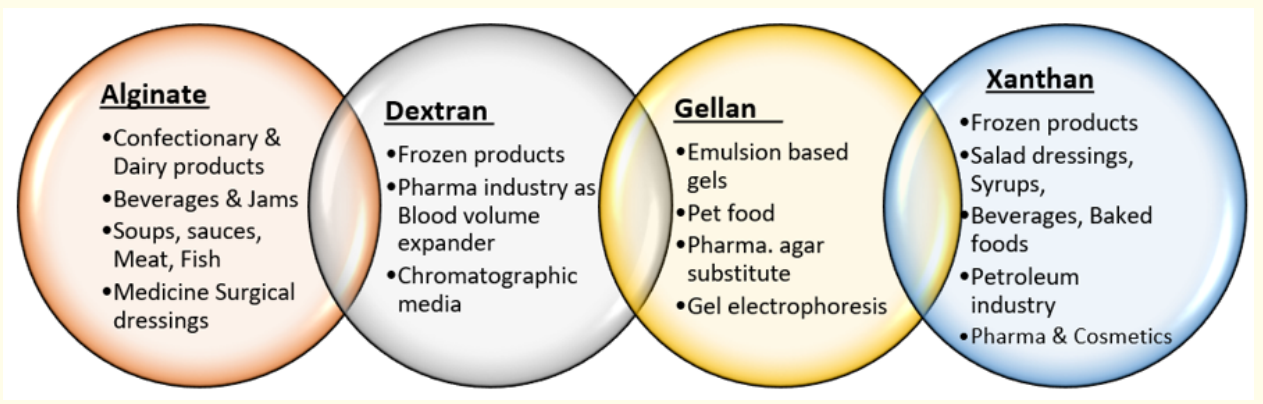

Figure 2

\section{What's next for microbe-derived polysaccharides?}

The polysaccharide market is estimated to be valued at USD 5.70 billion in 2015 and at USD 7.56 billion by 2020, is projected to grow at a CAGR of $5.8 \%$. The microbial polysaccharide market is driven by R\&D and innovations. Food manufacturers focus on high R\&D expenditures to provide high quality innovative hydrocolloids to cater to the increasing demand in processed and convenience foods. Present research is bent towards exploiting new sources of polysaccharides especially from marine extremophilic and xerophytic microorganisms. Several groups are developing polymeric matrices with altered properties for diverse applications; for example, Xanthans, sulfated dextran and sulfated curdlan are being studied for antiviral and anticancer properties.

What are current challenges and the future?

Despite the great diversity of molecular structures, only a few microbial gums have been commercially developed. The main limitations to commercialization are their production costs mostly related to substrate cost, availability in limited geographical areas, cultivation challenges and downstream processing. Strong research is required in the areas of analytical and purification of new gums. Metabolic engineering of gum producing strains has been attempted for production of xanthan, gellan, bacterial cellulose and levan. Applications of edible polysaccharide films in food technology open new opportunities for producing innovative biodegradable food packaging as an alternative for replacing synthetic plastics and reducing the impact of pollution on the global environment.

\section{Acknowledgment}

The authors are very thankful to their respective affiliation institutes for encouraging publishing of such awareness articles for wide readers of the journal. Authors of the article hereby gratefully acknowledge the Editor and senior management of the monthly periodical titled 'Abhineet' published by 'Asha Foundation (https:// indiaasha.org/J' for approving the copyrights for the publication of the article, which was published in 'Abhineet' in the joint issue of January 2020. The authors are also thankful to Shivani G. Mahajan for drawing, painting and providing the apt and creative painting for this article.

\section{Volume 4 Issue 7 July 2021 \\ (c) All rights are reserved by Girish B Mahajan and Dipali Rahul Phatak.}

